\title{
ВОЗМОЖНОСТИ ИСПОЛЬЗОВАНИЯ ОФИЦИАЛЬНЫХ ИНТЕРНЕТ-РЕСУРСОВ В ПРОЦЕССЕ САМОСТОЯТЕЛЬНОЙ РАБОТЫ СТУДЕНТОВ ПРИ ОБУЧЕНИИ ИСПАНСКОМУ ЯЗЫКУ
}

\section{THE POSSIBILITIES OF RELYING ON OFFICIAL INTERNET-RESOURCES FOR STUDENTS OF SPANISH AS A SECOND LANGUAGE IN A SELF-LEARNING ENVIRONMENT}

\section{E. Terentieva \\ A. Gorenko \\ Yu. Karpova}

Summary: The research is dedicated to the analysis of official Spanish Internet-resources, which may serve as additional materials for selfstudy purposes among the students of the Spanish language. The authors place extra emphasis of the significance of works made available by the Royal Spanish Academy of the Spanish Language. Also under analysis are the online resources of the Cervantes Institute. Based on the survey conducted among the students of the Humanities, a conclusion is made about the necessity to orient learners in the direction of working with competent Internet-resources.

Keywords: Learning Spanish, Internet-resources, Royal Spanish Academy, the Cervantes Institute.

\section{Терентьева Екатерина Дмитриевна}

К.филол.н., доцент, Российский университет дружбы народов (2. Москва)

terentyeva-ed@rudn.ru

Горенко Анна Александровна

К.филол.н., доцент, Московский государственный институт международных отношений (Университет)

МИДРФ

belanna_77@mail.ru

Карпова Юлия Анатольевна

К.филол.н., доцент, Московский государственный университет имени М. В. Ломоносова karpovamsu@gmail.com

Аннотация: Статья посвящена анализу основных официальных испанских интернет-ресурсов, которые могут служить дополнительным материалом в процессе самостоятельной работы студентов при языковом обучении. Авторы обращают особое внимание на значимость работ Королевской Академии испанского языка. Анализируются также некоторые онлайн-ресурсы Института Сервантеса. На основании опроса студентов гуманитарных специальностей делается вывод о необходимости большего ориентирования учащихся на работу с компетентными интернет-источниками.

Ключевые слова: обучение испанскому языку, интернет-ресурсы, Королевская Академия испанского языка, Институт Сервантеса.
$\mathrm{B}$ новых условиях пандемии коронавирусной инфекции COVID-19, когда подавляющее большинство высших учебных заведений в мире и в том числе в Российской Федерации перешли на дистанционные формы обучения, перед преподавателями встает сложная задача обеспечения студентов ресурсами для самостоятельной работы. Невозможность посещения библиотек и научных центров может негативно сказаться не только на процессе обучения иностранным языкам, но и на научной работе как преподавателей, так и студентов. Цель нашей статьи - описать некоторые из возможных испанских официальных интернет-ресурсов, которые могут использовать в процессе учебной и научной работы изучающие и преподающие испанский язык в РФ.

Необходимо напомнить тот важный факт, что за последние 20 лет филологи Испании и Америки проделали огромную практическую работу по укреплению единства испаноязычного мира, по-новому осмысляя сложнейшие теоретические вопросы языковой нормы и языкового варьирования. Целые коллективы ученых поставили перед собой цель не только создать досто- верное и подробное описание всего богатства существующих форм испанского языка, как родного языка населения десятков стран в Европе, Америке, Азии и Африке, но и сформулировать по возможности единые нормативные предписания для всех регионов. И эти предписания должны обязательно учитываться в процессе преподавания испанского языка на современном этапе.

За последние десятилетия Королевская Академия испанского языка совместно с Академиями испанского языка еще 22 стран, входящих в состав Ассоциации (ASALE) (Академия языка Экваториальной Гвинеи вошла состав Ассоциации ее 23 членом в 2016 г.), достаточно четко сформулировала свой подход к проблеме единого общеиспанского литературного языка и проделала значительную практическую работу по фиксации и закреплению определенного языкового стандарта.

«Академия признает, что в действительности испанский язык представляет собой совокупность различных норм, которые вместе с тем основываются на широкой общей базе, которая находит свое выражение в литера- 
турной речи при формальном общении и демонстрирует удивительное сходство на всем испаноязычном пространстве, с небольшими колебаниями преимущественно на уровне фонетики и лексики. Именно эту форму Академия предлагает принять за «общеиспанский языковой стандарт», или «общеиспанский литературный язык» («el español estándar», «la lengua general culta»). Это тот язык, который преподают в школах, на котором хотят говорить те, кто стремится говорить правильно, который используется в публичных выступлениях или в средствах массовой информации, это язык научных и технических текстов. Это тот язык, который позволяет всем носителям испанского языка, независимо от их происхождения, без труда понимать друг друга» $[4$, с. 321-322].

За короткий промежуток времени под эгидой Королевской Академии испанского языка и Ассоциации Академий испанского языка был опубликован целый ряд фундаментальных трудов: «Общеиспанский словарь трудностей языка» (Diccionario panhispánico de dudas, 2005), «Новая грамматика испанского языка» (Nueva gramática de la lengua española, 2009-2011), «Орфография испанского языка» (Ortografía de la lengua española, 2010), «Словарь американизмов» (Diccionario de americanismos, 2010) и др.

Ученые из Академий испанского языка стремились к тому, чтобы представленные труды стали ориентиром для студентов и преподавателей испанского языка на различных уровнях обучения и содержали некие рекомендации для всех носителей языка. В связи с этим некоторые работы вышли дополнительно в виде сокращенных и облегченных версий для школьного или самостоятельного обучения. К сожалению, в России все эти работы в печатном виде малодоступны. Вместе с тем наши преподаватели и студенты могут пользоваться интернет-ресурсами Королевской Академии испанского языка (RAE).

Основные интернет-ресурсы RAE сосредоточены на ее сайте, где можно получить информацию из таких источников, как Diccionario de la lengua española, Diccionario panhispánico de dudas, Diccionario del español jurídico, Nuevo diccionario histórico del español, Diccionario de americanismos, Diccionario de autoridades (1726-1739), Nuevo tesoro lexicográfico de la lengua española, Nueva gramática de la lengua española (2009-2011), Ortografía de la lengua española (2010), справочно-информационное бюро «Español al día», социальная сеть Twitter с пометкой \#RAEconsultas, а также платформа «Enclave RAE» [3].

В частности, отдел «Español al día» был создан для расширения опции предоставления консультаций по лингвистическим вопросам, руководствуясь правилами использования языковых средств, единообразным, образцовым употреблением элементов современного испанского языка. Каждый пользователь может послать свой запрос в раздел лингвистических консультаций или же посмотреть список наиболее часто задаваемых вопросов.

C 15 февраля 2018 года RAE открыла новую платную лингвистическую интернет-платформу «Enclave RAE». Отличительной особенностью данного интернет-источника является, в частности, его ориентация на людей, профессионально занимающихся испанским языком: преподавателей, исследователей, студентов и т.п. Платформа объединяет все доступные интернет-ресурсы $\mathrm{RAE}, \mathrm{a}$, например, в разделе «Aula» даются материалы (пояснения, тексты, упражнения) для проведения учебных занятий по избранным темам [6].

В 2019 году мы провели опрос группы преподавателей испанского языка по использованию интернетресурсов Королевской Академии испанского языка в процессе подготовки к занятиям. Выяснилось, что 100\% преподавателей пользуются различными интернет-ресурсами, и около 75\% из опрошенных преподавателей регулярно используют сайт Королевской Академии испанского языка. По нашим сведениям, лишь 1 из 5 преподавателей имеет постоянную возможность пользоваться печатным изданием Ortografía de la lengua española (2010) и Nueva gramática de la lengua española (2009-2011), что вполне объясняет высокий процент обращения преподавателей к интернет-ресурсам Королевской Академии испанского языка.

Проведенный тогда же опрос студентов 2-4 курсов гуманитарных факультетов (за исключением филологов), ожидаемо показал, что 100\% студентов пользуются различными интернет-источниками при обучении испанскому языку. Вместе с тем, к интернет-ресурсам Королевской Академии испанского языка хотя бы один раз обратилось только около половины студентов.

Студентов просили в течение трех месяцев фиксировать свои запросы в интернет-ресурсах Королевской Академии испанского языка. В результате выяснилось, что примерно 60\% запросов относилось к лексике (написание иностранных заимствований, прежде всего, англицизмов, значение фразеологизмов, значение латиноамериканизмов); 25\% относилось к вопросам орфографии (ударение, написание топонимов, написание заглавных букв, аббревиатур) и 15\% обращались к различным отделам грамматики (образование множественного числа, род имен существительных, вопросы предложного управления). Незначительный процент запросов по грамматическим аспектам представляется вполне объяснимым достаточным присутствием этого материала в учебниках и учебных пособиях, по которым ведется обучение студентов в аудиториях. 
Как показал новый опрос, проведенный в апреле 2020 г. среди студентов 3-4 курсов гуманитарных факультетов (исключая филологический факультет), практически все они активно пользуются различными ресурсами, предоставляемыми современным Интернетом в процессе подготовки к занятиям по испанскому языку и в своей научной работе. Прежде всего это разного рода словари, Википедия, а также, естественно, испанская пресса онлайн и кинофильмы на испанском языке.

Из 82 опрошенных пользуются следующими источниками:

1. Онлайн словари - 73 человека.

2. Википедия на испанском языке - 42 человека.

3. Ресурсы RAE - 10 человек.

4. Научные статьи на испанском языке - 27 человек.

5. Испанская пресса онлайн - 50 человек.

6. Просмотр кинофильмов на испанском языке - 59 человек.

7. Чтение книг на испанском языке - 28 человек.

8. Курсы испанского языка онлайн - 8 человек.

9. Библиотечные ресурсы онлайн - 5 человек.

10. Другое - социальные сети, музыка, компьютерные игры, испанский интерфейс на смартфоне, аккаунты преподавателей языка в инстаграме) - 14 человек.

11. Никакими - 4 человека.

Это показывает, что, с одной стороны, опрошенные студенты активно используют возможности интернетисточников, но, с другой стороны, мы можем отметить необходимость более активного информирования студентов преподавателями о важности сайта Королевской Академии испанского языка для получения объективных сведений в процессе обучения испанскому языку.

Необходимость познакомиться с актуальными изменениями в испанской орфографии и невозможность в отдельных случаях получить сведения обо всем лексическом многообразии современных вариантов испанского языка из печатных источников требуют обращения к авторитетным источникам Королевской Академии испанского языка. Сложившаяся в мире сложная обстановка, связанная с карантинными мероприятиями, только многократно увеличивает значимость такого рода обращений.

Студенты могут прибегать к онлайн-консультации на сайте RAE при выполнении разного рода заданий, особенно при работе с текстами средств массовой информации и при написании научных исследований. Важно подчеркнуть, что сведения, получаемые именно на этом сайте, являются максимально достоверными и объективными, учитывающими все последние рекомендации нормативного характера. Такие актуализированные данные и должны лежать в основе процесса обучения испанскому языку на современном этапе. Это позволит избежать получения недостоверной или неполной информации из непроверенных источников.

Стоит отметить, что российские студенты к моменту поступления в высшие учебные заведения обычно уже хорошо знакомы с работой лингвистических сайтов на базе русского языка. Так, справочно-информационный портал Грамота.ру был создан в 2000 году. Он ведет просветительскую работу с интернет-пользователями, пропагандирует научные знания о русском языке и языках мира, предоставляет консультации в режиме онлайн о современных нормах русского языка, помощь в овладении нормами современного русского литературного языка и навыками совершенствования устной и письменной речи. Онлайн-раздел включает 10 электронных словарей русского языка, аудиословари, словарь русского арго, справочники по пунктуации и фразеологии, словарь трудностей, интерактивные диктанты, учебники и т.п. [1].

Еще одним официальным ресурсом при изучении испанского языка в период самоизоляции могут быть виртуальные курсы испанского языка «AVE Global» (El Aula Virtual de Español), осуществляемые Институтом Сервантеса - государственным учреждением Испании, созданным в 1991 году для преподавания испанского языка и распространения испанской и латиноамериканской культуры [2]. Из-за платного характера доступа к этим занятиям мы не можем рекомендовать их студентам, но считаем необходимым упомянуть о них, как об определенной возможности для повышения языковой компетенции. В то время как очные занятия временно прекращены во всем мире, общий рост занимающихся на заочных курсах AVE в марте 2020 года составил беспрецедентные 2600 \% по сравнению с любым месяцем 2019 года - почти 25 тысяч человек. Для сравнения скажем, что количество учащихся с помощью данной платформы за весь 2019 год составило 11 тысяч человек (917 человек в месяц в среднем). Кроме того, количество преподавателей на данных дистанционных курсах составило 1700 человек, что означает увеличение этого показателя на 3700 \%. Преподавателями на курсах AVE, как и ранее на очных курсах, являются штатные или внештатные преподаватели Института Сервантеса. Учащиеся, как и ранее, получают доступ к онлайн курсу с помощью дистанционных технологий, изучая не только грамматику или лексику испанского языка, но также и получая знания о разнообразии и богатстве испаноязычной культуры через ее литературу, музыку, кино, гастрономию, архитектуру и т.д. [5].

Проведенный анализ показывает, что студенты могут продуктивно использовать современные ресурсы, предоставляемые различными испанскими интернетисточниками. В условиях вынужденного дистанционно- 
го обучения это дает преподавателям дополнительные возможности для организации самостоятельной работы студентов. Вместе с тем, очевидно, что необходимо в большей степени ориентировать студентов на обраще- ние к официальным сайтам Королевской Академии испанского языка, которые содержат актуализированную информацию по вопросам современной испанской орфографии и языковой нормы.

\section{ЛИТЕРАТУРА}

1. Грамота.ру [электронный ресурc]. URL: www.gramota.ru (дата обращения: 20.04.2020)

2. Институт Сервантеса [электронный ресурc]. URL: https://moscu.cervantes.es/ru/o_nas_ispanskiy.htm (дата обращения: 20.04.2020)

3. Королевская Академия испанского языка [электронный ресурc]. URL: www.rae.es (дата обращения: 20.04.2020)

4. Терентьева Е.Д., Химич Г.А., Карпова Ю.А. К проблеме выработки общеиспанского языкового стандарта в начале XXI века // Филология: научные исследования, 2018, № 4, с. 316-325.

5. El Aula Virtual de Español aumentó en marzo un $2.600 \%$ los alumnos y un $3.700 \%$ los nuevos tutores, 08.04 .2020 [электронный pecypc]. URL: https://www. cervantes.es/sobre_instituto_cervantes/prensa/2020/noticias/aumento_alumnos_aula_virtual.htm (дата обращения: 20.04.2020)

6. Enclave RAE [электронный ресурс]. URL: http://www.rae.es/noticias/enclave-rae-la-nueva-plataforma-de-la-real-academia-espanola (дата обращения: 20.04.2020)

( Терентьева Екатерина Дмитриевна (terentyeva-ed@rudn.ru), Горенко Анна Александровна (belanna_77@mail.ru ), Карпова Юлия Анатольевна (arpovamsu@gmail.com).

Журнал «Современная наука: актуальные проблемы теории и практики»

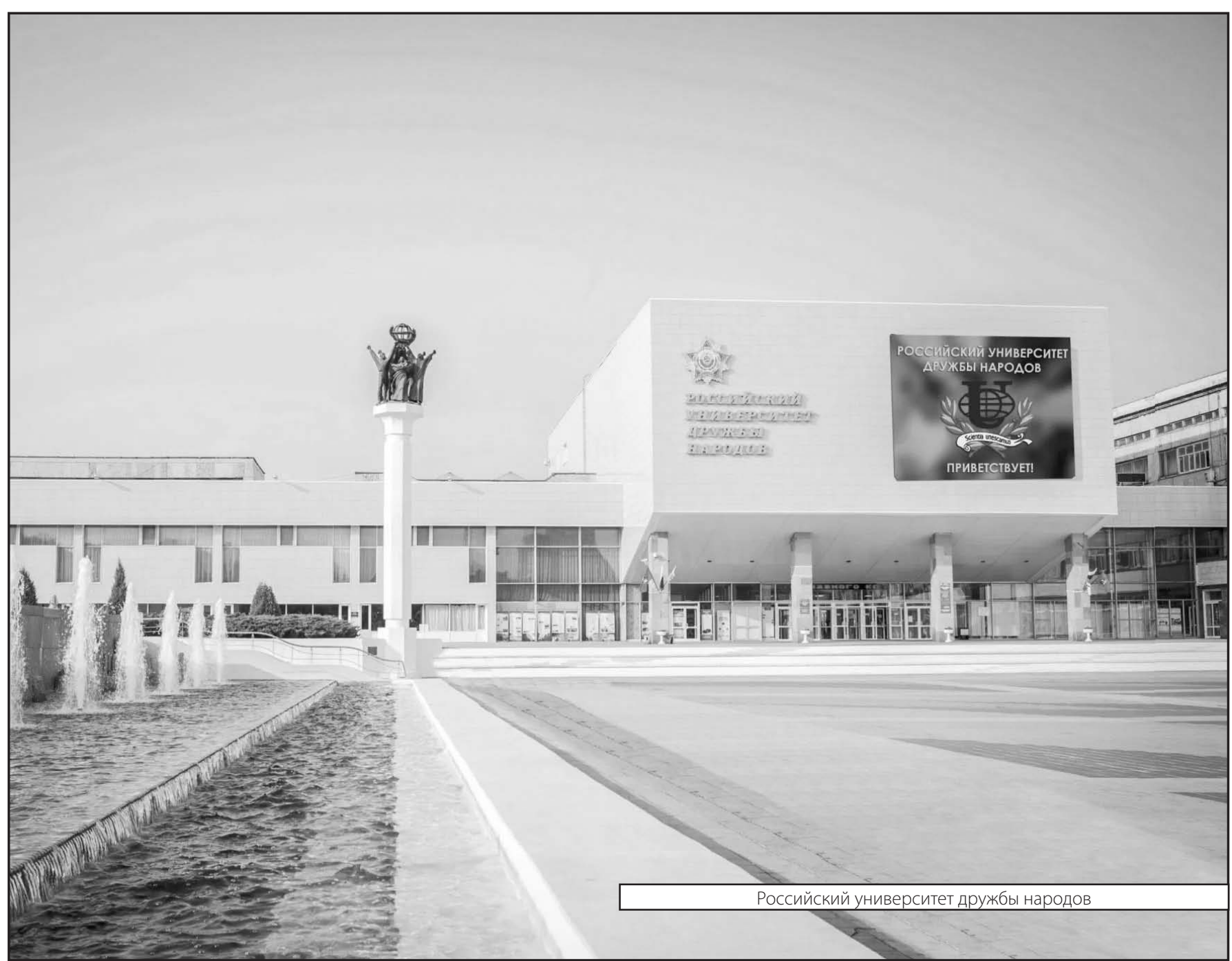

